\title{
16 Promotion of physical activity among older adults
}

\section{Is social marketing an effective method?}

\author{
Luc Goethals, Nathalie Barth, David Hupin, \\ Frederic Roche, Karine Gallopel-Morvan and \\ Bienvenu Bongue
}

\begin{abstract}
Social marketing is "the adaptation of commercial marketing technologies to programs designed to influence the voluntary behavior of target audiences to improve their personal welfare and that of the society". Social marketing is one of the most widely used methods for promoting behaviors that benefit the health of the population. That social marketing is effective has been proven in certain interventions and certain populations, such as smoking prevention as well as obesity prevention among young people. Although this method has shown its value in other contexts, its use and evaluation in getting seniors to take part in regular physical activity (PA) remains limited. This chapter presents a literature review conducted to identify interventions using the social marketing method to promote PA among elderly people. Our aim was to analyze whether social marketing can have potential to promote PA among elderly people.

As shown in this literature review, social marketing may have the potential to be effective for promoting PA among seniors. However, further research is needed since the studies we identified are not amenable to meta-analysis.
\end{abstract}

\section{Introduction}

Population ageing is the result of a falling birth rate and a rising life expectancy. Between 2015 and 2050, global projections show that the proportion of over 60-year-olds in world population should rise from 12 to 22 percent, representing nearly two billion people (World Health Organization, 2018).

Although increasing our life expectancy is important for humanity, so too is preserving functional autonomy to maintain a certain quality of life and manage health resources (Lau, Ohinmaa and Johnson, 2011).

Falls are the primary cause of death among over $65 \mathrm{~s}$, affecting one in three people in this age group (Gillespie et al., 2012). Physical activity (PA) represents the most effective method for preventing falls among older citizens (Gillespie et al., 2012; Grossman et al., 2018) while PA interventions focusing on balance are the most effective way of preventing loss of autonomy among older adults living at home (Liu-Ambrose et al., 2019; Sherrington et al., 2017).

However, though there is now agreement that PA is effective in practice, there are many barriers to participation (Hughes et al., 2005; Schutzer and Graves, 2004). Indeed, several such barriers exist among the elderly, such as a belief of no longer being able to participate 


\section{4}

L. Goethals et al.

because of a loss of physical capacity, an image of sport as being for young, healthy people, and poor awareness of the tailored activities on offer. That is why, all in all, only a small number of older adults participate in PA for fall prevention (Bongue et al., 2016).

Social marketing is one of the most widely used methods for promoting behaviors that benefit the health of the population (Gallopel-Morvan, 2014). That social marketing is effective has been proven in certain interventions and certain populations, such as smoking prevention as well as obesity prevention among young people (Stead et al., 2007). As regards PA, authors have identified a number of effective techniques for promoting it among older adults (Zubala et al., 2017). One of these is social marketing, which involves "the adaptation of commercial marketing technologies to programs designed to influence the voluntary behavior of target audiences to improve their personal welfare and that of the society" (Andreasen, 1995). The social marketing method is based on seven criteria. These are the aim of the intervention, analysis of the target audience, segmentation, exchange, marketing mix, competition and assessment (Hastings and Domegan, 2017).

Although this method has shown its value in other contexts, its use and evaluation in getting older adults to take part in regular PA remains limited (Fujihira et al., 2015). Our aim was to conduct a systematic literature review on the use and potential effectiveness of social marketing in interventions to promote PA among over 60 -year-olds.

\section{Method}

We analyzed social marketing interventions aiming to increase PA among over 60-yearolds whose results were published in French or English in peer-reviewed journals between January 2008 and July 2019.

Web of Science, MEDLINE and EBSCOhost were the three databases analyzed. The keywords used were: physical+activit* or exercis* and intervention* or Randomized Controlled Trial or trial or evaluation or campaign* or program* or study or studies and social marketing.

Papers were selected for analysis if the interventions presented used some or all of the social marketing approach as defined by researchers in the field (French and Gordon, 2015; Hastings and Domegan, 2017; Lee and Kotler, 2016). Specifically:

- Behavioral change was the primary objective of the intervention (i.e., increase PA).

- Qualitative and/or quantitative studies were conducted on the target audiences to better understand their characteristics, habits and needs.

- The target audience was segmented based on various criteria (sex, social background, etc.) and specific interventions were offered to the segments identified.

- The exchange concept was implemented. In other words, in return for changing behavior, individuals were offered "benefits" and advantages to motivate them to take part in more PA, for example a financial or material reward in line with an indicator of change.

- The marketing mix was implemented on the ground, i.e., commercial marketing tools were used to achieve the objectives of promoting PA. There are five such tools: Influencers (work with partners on the ground, like associations, companies), Behavior (recommend and facilitate the adoption of the behavior), Cost (offer financial support mechanisms to combat financial and/or psychological barriers to adopting the behavior), Ease of Access (facilitate access to services or products that enable a change in the target behavior), and Communication (promote the behavior through the use of communication tools) (Gallopel-Morvan, 2014). 
- A competitor analysis was performed (and factored into the program) to identify any issues that could hinder the adoption of the proposed change to increase PA, for example the existence of other organizations and/or competing programs.

- An assessment of the program.

The interventions selected in our paper had to have implemented at least four of the seven benchmark criteria of social marketing identified by researchers in the field. The exclusion criteria were: papers that did not use the social marketing approach, interventions aimed at children and adults under 60, and interventions that did not target PA.

All papers were compiled using Zotero 5.0.73. Their titles and abstracts were then studied. In the end, of 505 documents selected from the databases, only eight met our chosen criteria, to which one additional paper meeting the inclusion criteria was added (see Appendix 3). These nine papers corresponded to six interventions.

\section{Results}

Of the six interventions selected, five (DiGuiseppi et al., 2014; Kamada et al., 2018; Varma et al., 2016; Wilson et al., 2015; Withall, Jago and Fox, 2012) had a positive effect on participants, increasing participation in the activities offered and/or increasing the level of PA. One study was not assessed (Newton et al., 2015).

Of the studies selected, two specifically targeted over 60-year-olds (DiGuiseppi et al., 2014; Varma et al., 2016) whereas the others segmented the population into subcategories, one of which was over 60 -year-olds.

Behavioral objective. The five interventions that had a positive effect on PA developed programs oriented toward specific goals. Carolyn DiGuiseppi et al. (2014) aimed to increase the attractiveness of balance classes for over 60 -year-olds in selected churches. Dawn Wilson et al. (2015) aimed to improve the social and physical environment of lowincome African-American communities in the study area, specifically via the promotion of walking. Janet Withall et al. (2012) conducted a study that aimed to increase recruitment and adherence in a PA program in a low-income area. Masamitsu Kamada et al. (2018) aimed to increase the proportion of people aged 40 to 79 participating in aerobic, flexibility and/or muscle-strengthening activities in Unnan, Japan. Lastly, Vijay Varma et al. (2016) aimed to increase walking levels among over 60 -year-olds recruited as volunteers into public schools in the US city of Baltimore.

Population analysis. The five interventions conducted interview-based market studies to define the needs, barriers, etc., of the population. Withall et al. (2012) employed a mixed method, using a questionnaire to assess people's motivation to take part in group PA along with group interviews.

Segmentation. Of the five interventions that had a positive effect, three reported the use of segmentation. In the study by Withall et al. (2012), the segmentation criterion was sex. The target population mainly comprised women educated on the benefits of PA. The intervention focused on reducing barriers such as the fear of going to an activity alone. In the study by Wilson et al. (2014), two of the main segmentation criteria were being AfricanAmerican and being aged over 18 years old. Lastly, in the study by Kamada et al. (2018), the researchers used a model to determine a primary communication target segment. Women aged 60 to 79 years were the primary target of their study.

Exchange. The five interventions implemented the exchange concept by using incentives. In the study by DiGuiseppi et al. (2014), participants received $\$ 5$ if they took part in 
the classes on offer, while the leaders of the churches involved in the program received gift cards worth $\$ 55$ to thank them for their churches' participation. The church leaders were tasked with facilitating the transmission of messages and communications to the study's target audience. Withall et al. (2012) offered the first six weeks of sessions free of charge in their intervention, after which the price rose to $£ 1$ per session. A low price was used to attract low-income individuals to the sessions. In the study by Wilson et al. (2015), participants received a $\$ 20$ gift card for each assessment period as well as a $\$ 40$ gift card for the assessment at 24 months. Lastly, in the study by Varma et al. (2016), participants received financial compensation for the time they volunteered as well as $\$ 25$ for taking part in an assessment and $\$ 10$ for a telephone interview.

Marketing mix. The five interventions used the marketing mix principles to set up their program. For example, in the intervention by DiGuiseppi et al. (2014), the "product" was a fall prevention class, while the communication involved distributing flyers or newsletters promoting these classes. They selected churches as their location to facilitate access to the target audience, and the cost of the classes was \$20. Cost is one of the psychological barriers to taking part in PA, but it is important to remember that this cost includes more than just the admission fee. It also includes the number of sessions, their frequency and the distance from home, not to mention the fear of falling or aggravating existing pain. To reduce these barriers to their program, the classes of DiGuiseppi et al. were conducted in a "safe, comfortable environment", with regular classes on offer at times suited to the intervention's target audience.

Competition. The intervention by DiGuiseppi et al. (2014) was the only one that identified a facility that competed with their program. That facility was a wellness center offering exercise programs for over 60 -year-olds.

Assessment. Of the interventions that had a positive impact on changing PA habits, that of Wilson et al. (2015) assessed participation data and psychosocial data from participants at baseline as well as at 12, 18 and 24 months after the intervention. They revealed that uptake was higher among PATH trial participants who received information on the PA program. Walking attendance was greater among these participants than among those who received no information. Over a period of nine months, the number of walkers rose from 40 to 400 per month in the social marketing intervention group (Wilson et al., 2015).

Withall et al. (2012) showed that enrollment in the different PA classes (dance, gym and balance sessions) had increased since the start of the program, that attendance levels were steady and that adherence was good.

Varma et al. (2016) reported an increase in walking among women in the social marketing intervention group, with their daily step counts rising by a mean of 1500 .

Kamada et al. (2018) showed that their intervention increased the level of each type of PA promoted in their target population. That was a five-year study, with the first positive results having appeared progressively over a period of several years.

DiGuiseppi et al. (2014) aimed to assess class participation and information retention by participants. Their intervention showed that the program implemented in the churches succeeded in motivating older adults to join PA classes. The participants were also more likely to remember information about fall prevention.

Table A4.1 (Appendix 4) shows an assessment of the use of the seven social marketing benchmark criteria as defined by researchers in social marketing. None of the six interventions selected for this literature review implemented the entire social marketing approach. In other words, none met all of the seven criteria presented above. Four of the six interventions employed six of the criteria (DiGuiseppi et al., 2014; Kamada et al., 2015, 2013; 
Wilson et al., 2015; Withall et al., 2012), one intervention employed five (Varma et al., 2016) and one employed four (Newton et al., 2015).

\section{Discussion and conclusion}

This systematic literature review aimed to ascertain whether using social marketing in interventions to promote PA among over 60 -year-olds was useful for improving the effectiveness of programs. Our study shows that social marketing has the potential to be effective in promoting PA among older adults. Our results are in line with those in the literature (Baril and Paquette, 2016; Fujihira et al., 2015). So far, very few studies have been published on this topic. In fact, only nine papers representing six interventions were identified in the scientific databases. Of these six, five concluded that social marketing was useful for promoting PA among the elderly. The five studies that reported a positive assessment of their programs believed their success to be mainly due to three factors, specifically: the use of social marketing techniques through the implementation of a number of criteria; the funding of the activities, which made it possible to tackle financial barriers; and the building of social ties between participants in the programs, which provided them with support and interaction. For instance, Varma et al. (2016) suggest that walking levels increased among women because they were taking part in a new voluntary activity. Kamada et al. $(2013,2015)$ state that their studies did not succeed in demonstrating an increase in PA levels at one and three years because the program's approach was not comprehensive enough. For that reason, they suggested that a strategy of modifying the environment by improving the public transport system and building facilities specifically for PA could facilitate the meeting of recommended PA levels. And yet at five years after the launch of the study, Kamada et al. (2018) showed that their intervention had had a positive effect. The study by Newton et al. (2015) has not yet been analyzed.

The interventions identified in our systematic review all used the marketing mix and its "4Ps": Price, Place, Promotion and Product. The 4Ps represent a group of operational areas for which strategies need to be developed. However, there is currently debate. For instance, Gallopel-Morvan (2019) believes that the 4Ps may be more suited to commercial than noncommercial marketing. Instead, they advance five criteria (Influencers, Behavior, Cost, Ease of Access and Communication) potentially more suited to social marketing and behavioral change.

It is difficult to say whether social marketing is useful in promoting PA among older adults since none of the six interventions selected used the entire approach (i.e., all seven benchmark criteria). Yet Haruka Fujihira et al. (2015) showed that the more a program uses the social marketing benchmark criteria defined by A.R. Andreasen (1995), the more it becomes effective at changing the behavioral habits of target audiences. Literature reviews such as those by Carins and Sharyn Rundle-Thiele (2014), Pang, Kubacki and RundleThiele (2017) and Stead et al. (2007) have classed social marketing interventions according to the same benchmark criteria as Andreasen, and have reported similar findings to those of Fujihira et al. (2015). Hence further studies that implement the seven benchmark criteria identified in this literature review are needed to assess the potential effectiveness of this technique of social marketing.

Additionally, the papers that we selected in this review comprise certain limitations in terms of assessment method, group heterogeneity and contamination risk. The assessment models chosen preclude any definite direct attribution of the positive results to any one part of the intervention or any combination of activities. In a number of studies, discrepancies 
between the intervention and control groups interfered with the assessment of change between them. Withall et al. (2012) suggested that the groups had differences (particularly in terms of age and ethnic origin) which prevented them from making direct comparisons during the assessment. Kamada et al. (2015) thought that the results of their study were contaminated because the control group may have been exposed to the social marketing campaign developed for the intervention group. This may have been due to the geographical proximity of the groups and word-of-mouth. What's more, the criteria selected for assessing the prevention programs were not always the same, making it difficult to compare the interventions, or were insufficient to measure effectiveness. For instance, in the study by Withall et al. (2012), the criteria only gauged PA program participation, without measuring PA levels, PA intensity or biological markers.

Different age groups (children, adults, older adults) have specific characteristics and guidelines in terms of public health and necessitate that separate social marketing interventions be designed for each one. Given both the paucity of studies on using social marketing principles to promote PA in older adults as well as the lack of conclusive evidence in those studies, it may be wondered whether the use of social marketing is appropriate in the geriatric population, particularly where PA is concerned (Fujihira et al., 2015).

Demographic projections show that the population of over 60-year-olds may represent nearly two billion people between now and 2050 (World Health Organization, 2018). Since PA has been identified as one of the effective interventions for healthy ageing (Lamboy et al., 2018) and since a large proportion of older adults are not active enough, targeted social marketing programs could help prevent numerous health problems associated with inactivity (Fujihira et al., 2015; Taylor, 2014). As shown in this literature review, social marketing may have the potential to be effective for promoting PA among older adults. However, further research is needed since the studies we identified are not amenable to meta-analysis. This is because the heterogeneity of the backgrounds of the studies selected along with the differing measures of their results render the standard methods of metaanalysis impracticable.

\section{References}

Andreasen, A.R. (1995). Marketing social change. 1st ed. San Francisco, CA: Jossey-Bass.

Baril, G. and Paquette, M.-C. (2016). L'efficacité du marketing social en promotion des saines habitudes de vie. Available at: www.inspq.qc.ca/publications/2141 [Accessed 29 August 2019].

Bongue, B., Hugues, J., Achour, É., Colvez, A. and Sass, C. (2016). Mieux prévenir les chutes chez les personnes âgées. Soins Gerontologie, 21(120), 24-29. doi.org/10.1016/j.sger.2016.05.006.

Carins, J.E. and Rundle-Thiele, S.R. (2014). Eating for the better: a social marketing review (2000-2012). Public Health Nutrition, 17(7), 1628-1639. doi.org/10.1017/S1368980013001365.

DiGuiseppi, C.G., Thoreson, S.R., Clark, L., Goss, C.W., Marosits, M.J., Currie, D. W. and Lezotte, D.C. (2014). Church-based social marketing to motivate older adults to take balance classes for fall prevention: cluster randomized controlled trial. Preventive Medicine, 67, 75-81. doi.org/ 10.1016/j.ypmed.2014.07.004.

French, J. and Gordon, R. (2015). Strategic social marketing. Los Angeles, CA: Sage.

Fujihira, H., Kubacki, K., Ronto, R., Pang, B. and Rundle-Thiele, S. (2015). Social marketing physical activity interventions among adults 60 years and older: a systematic review. Social Marketing Quarterly. doi.org/10.1177/1524500415606671.

Gallopel-Morvan, K. (2014). Marketing social et marketing social critique: quelle utilité pour la santé publique ? Les Tribunes de la santé, 45(4), 37. doi.org/10.3917/seve.045.0037.

Gallopel-Morvan, K. (2019). Le marketing social: de la comprehension des publics aux changements de comportement. Rennes: Ehesp. 
Gillespie, L.D., Robertson, M.C., Gillespie, W.J., Sherrington, C., Gates, S., Clemson, L.M. and Lamb, S.E. (2012). Interventions for preventing falls in older people living in the community. Cochrane Database of Systematic Reviews, (9). doi.org/10.1002/14651858.CD007146.pub3.

Grossman, D.C., Curry, S.J., Owens, D.K., Barry, M.J., Caughey, A.B., Davidson, K. W., Doubeni, C.A., Epling, J.W. Jr, Kemper, A.R., Krist, A.H., Kubik, M., Landefeld, S., Landefeld, S., Mangione, C.M., Pignone, M., Silverstein, M., Simon, M.A. and Tseng, C.-W. (2018). Interventions to prevent falls in community-dwelling older adults: US preventive services task force recommendation statement. JAMA, 319(16), 1696-1704. doi.org/10.1001/jama.2018.3097.

Hastings, G. and Domegan, C. (2017). Social marketing: rebels with a cause. Oxford: Routledge.

Hughes, S.L., Williams, B., Molina, L.C., Bayles, C., Bryant, L.L., Harris, J.R., Hunter, R., Ivey, S. and Watkins, K. (2005). Characteristics of physical activity programs for older adults: results of a multisite survey. The Gerontologist, 45(5), 667-675. doi.org/10.1093/geront/45.5.667.

Kamada, M., Kitayuguchi, J., Abe, T., Taguri, M., Inoue, S., Ishikawa, Y., Bauman, A., Lee, I.M., Miyachi, M. and Kawachi, I. (2018). Community-wide intervention and population-level physical activity: a 5-year cluster randomized trial. International Journal of Epidemiology, 47(2), 642-653. doi.org/10.1093/ije/dyx248.

Kamada, M., Kitayuguchi, J., Abe, T., Taguri, M., Inoue, S., Ishikawa, Y., Harada, K., Lee, I.M., Bauman, A. and Miyachi, M. (2015). Community-wide promotion of physical activity in middleaged and older Japanese: a 3-year evaluation of a cluster randomized trial. International Journal of Behavioral Nutrition and Physical Activity, 12, 82. doi.org/10.1186/s12966-015-0242-0.

Kamada, M., Kitayuguchi, J., Inoue, S., Ishikawa, Y., Nishiuchi, H., Okada, S., Harada, K., Kamioka, H. and Shiwaku, K. (2013). A community-wide campaign to promote physical activity in middleaged and elderly people: a cluster randomized controlled trial. International Journal of Behavioral Nutrition and Physical Activity, 10, 44. doi.org/10.1186/1479-5868-10-44.

Lamboy, B., Cotton, N., Hamel, E. and Soleymani, D. (2018). Vieillir en bonne santé: revue des interventions efficaces. La santé en action, (446), 4.

Lau, R.S., Ohinmaa, A. and Johnson, J.A. (2011). Predicting the future burden of diabetes in Alberta from 2008 to 2035. Canadian Journal of Diabetes, 35(3), 274-281. doi.org/10.1016/S14992671(11)53011-4.

Lee, N.R. and Kotler, P. (2016). Social marketing. 5th ed. Los Angeles, CA: Sage.

Liu-Ambrose, T., Davis, J.C., Best, J.R., Dian, L., Madden, K., Cook, W., Hsu, C.L. and Khan, K.M. (2019). Effect of a home-based exercise program on subsequent falls among community-dwelling high-risk older adults after a fall: a randomized clinical trial. JAMA, 321(21), 2092-2100. doi. org/10.1001/jama.2019.5795.

Newton, J.D., Klein, R., Bauman, A., Newton, F.J., Mahal, A., Gilbert, K., Piterman, L., Ewing, M.T., Donovan, R.J. and Smith, B.J. (2015). The MOVE study: a study protocol for a randomised controlled trial assessing interventions to maximise attendance at physical activity facilities. $B M C$ Public Health, 15, 403. doi.org/10.1186/s12889-015-1735-0.

Pang, B., Kubacki, K. and Rundle-Thiele, S. (2017). Promoting active travel to school: a systematic review (2010-2016). BMC Public Health, 17(1), 638. doi.org/10.1186/s12889-017-4648-2.

Schutzer, K.A. and Graves, B.S. (2004). Barriers and motivations to exercise in older adults. Preventive Medicine, 39(5), 1056-1061. doi.org/10.1016/j.ypmed.2004.04.003.

Sherrington, C., Michaleff, Z.A., Fairhall, N., Paul, S.S., Tiedemann, A., Whitney, J., Cumming, R.G., Herbert, R.D., Close, J.C.T. and Lord, S.R. (2017). Exercise to prevent falls in older adults: An updated systematic review and meta-analysis. British Journal of Sports Medicine, 51(24), 1750-1758. doi.org/10.1136/bjsports-2016-096547.

Stead, M., Gordon, R., Angus, K. and McDermott, L. (2007). A systematic review of social marketing effectiveness. Health Education, 107(2), 126-191. doi.org/10.1108/09654280710731548.

Taylor, D. (2014). Physical activity is medicine for older adults. Postgraduate Medical Journal, 90(1059), 26-32. doi.org/10.1136/postgradmedj-2012-131366.

Varma, V.R., Tan, E.J., Gross, A.L., Harris, G., Romani, W., Fried, L.P., Rebok, G.W. and Carlson, M.C. (2016). Effect of community volunteering on physical activity: a randomized controlled trial. American Journal of Preventive Medicine, 50(1), 106-110. doi.org/10.1016/j.amepre.2015.06.015. 
Wilson, D.K., van Horn, M.L., Siceloff, E.R., Alia, K.A., St George, S.M., Lawman, H.G., Trumpeter, N.N., Coulon, S.M., Griffin, S.F., Wandersman, A., Egan, B., Colabianchi, N., Forthofer, M. and Gadson, B. (2015). The results of the "positive action for today's health" (PATH) trial for increasing walking and physical activity in underserved African-American communities. Annals of Behavioral Medicine: A Publication of the Society of Behavioral Medicine, 49(3), 398-410. doi. org/10.1007/s12160-014-9664-1.

Withall, J., Jago, R. and Fox, K.R. (2012). The effect of a community-based social marketing campaign on recruitment and retention of low-income groups into physical activity programmes: a controlled before-and-after study. BMC Public Health, 12, 836. doi.org/10.1186/1471-2458-12-836.

World Health Organization (2018). Vieillissement et santé. Available at: www.who.int/mediacentre/ factsheets/fs404/fr/ [Accessed 29 August 2019].

Zubala, A., MacGillivray, S., Frost, H., Kroll, T., Skelton, D.A., Gavine, A., Gray, N.M., Toma, M. and Morris, J. (2017). Promotion of physical activity interventions for community dwelling older adults: a systematic review of reviews. PLOS ONE, 12(7). doi.org/10.1371/journal.pone.0180902. 